\title{
EFFECT OF A STRUCTURED MOTHERS CLASS VERSUS ONE-ON-ONE LECTURE ON \\ POSTPARTUM AND NEONATAL OUTCOMES IN A TERTIARY GOVERNMENT HOSPITAL: A DOUBLE BLIND RANDOMIZED CONTROLLED TRIAL \\ BANDELARIA, Pamela MD; WONG, Jennie MD; NUNEZ, Carlos Jr MD \\ Ospital ng Maynila Medical Center, Department of Pediatrics \\ Manila, Philippines
}

\section{BACKGROUND}

Majority of under-five mortalilty rates are neonates. Strategies in improving postpartum care can lead to decreased neonatal morbidity and mortality.

\section{OBJECTIVE}

To determine effect of a structured mothers class on postpartum care and neonatal outcome in a government hospital. Null hypothesis states there is no significant difference between control and treatment group on maternal postpartum knowledge, attitudes, practices and neonatal outcomes.

\section{STUDY DESIGN}

Double blind, randomized controlled trial set in a government hospital from September to October 2017. Participants are stable mother-singleton neonates delivered vaginally, with no congenital anomalies or signs and symptoms of infection. Total of 110 participants were enrolled, with 8 dropouts.

\section{METHODOLGY}

Consenting participants were randomly assigned to a control group (conventional lecture on post partum care) and treatment group (structured mothers class of two $20 \mathrm{~min}$ lectures on postpartum care). A self-made, pre tested questionnaire was used to measure knowledge, attitude, practices of mothers on postpartum care. Secondary outcomes were neonatal morbidity and mortality. Chi-square analysis was used to compare proportions, paired t test for continuous data, Wilcoxon rank-sum test for nonparametric data. Statistical significance was set at $p<0.05$. Intention to treat analysis was done.

\section{RESULTS}

There was a significant difference between groups in postpartum knowledge and practices ( $p$ value $<0.05$ ). There is no significant difference in neonatal outcomes ( $p$ value $>0.05$ ).

\section{CONCLUSION}

The mothers class is more effective in postpartum care knowledge and practices as the null hypothesis was rejected. Further studies can allow implementation in larger communities.

Table 1. Knowledge, Attitude and Practices on Postpartum Care for Conventional and Treatment Group

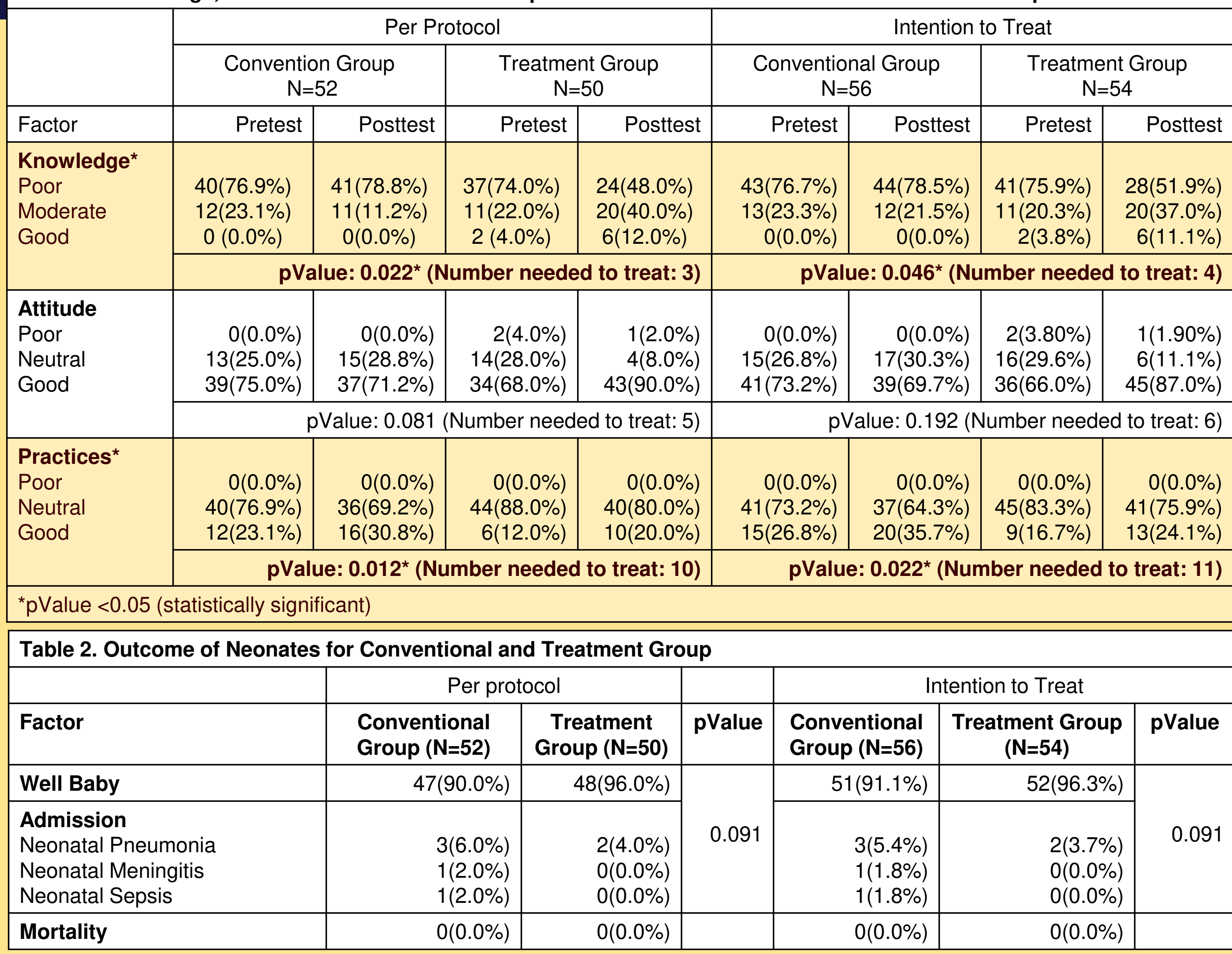

